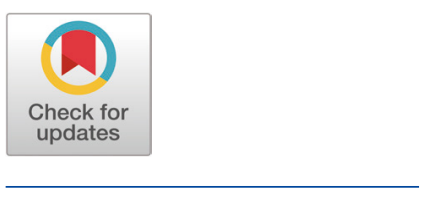

Received: Dec 30, 2019

Revised: Jan 7, 2020

Accepted: Jan 10, 2020

*Corresponding author Ki Hyun Kim

National Institute of Animal Science, Rural Development Adiministration,

Wanju 55365, Korea.

Tel: +82-63-238-7052

E-mail: kihyun@korea.kr

Copyright $\odot 2020$ Korean Society of Animal Sciences and Technology.

This is an Open Access article distributed under the terms of the Creative Commons Attribution Non-Commercial License (http:// creativecommons.org/licenses/bync/4.0/) which permits unrestricted non-commercial use, distribution, and reproduction in any medium, provided the original work is properly cited.

ORCID

Ju Lan Chun

https://orcid.org/0000-0002-4618-586X Han Tae Bang

https://orcid.org/0000-0003-0441-3542 Sang Yun Ji

https://orcid.org/0000-0001-7235-3655

Jin Young Jeong

https://orcid.org/0000-0002-8670-7036 Minji Kim

https://orcid.org/0000-0003-2106-1921

Byeonghyeon Kim

https://orcid.org/0000-0001-9298-3160

Sung Dae Lee

https://orcid.org/0000-0002-9167-4099

Yoo Kyung Lee

https://orcid.org/0000-0002-9896-4152

\section{Comparison of sample preparation procedures of inductively coupled plasma to measure elements in dog's hair}

Ju Lan Chun, Han Tae Bang, Sang Yun Ji, Jin Young Jeong, Minji Kim, Byeonghyeon Kim, Sung Dae Lee, Yoo Kyung Lee, Kondreddy Eswar Reddy and Ki Hyun Kim*

National Institute of Animal Science, Rural Development Administration, Wanju 55365, Korea

\section{Abstract}

The pre-treatment condition affects on the element analysis of inductively coupled plasma (ICP). In this study the pre-treatment condition of ICP has been studied to quantify elements in dog's hair. The hair samples were collected from twelve female Beagles by clipping them into 1 or $2 \mathrm{~cm}$ at the back neck. The qualitative and quantitative analysis of elements in hairs were performed by using ICP. By ICP nine elements were qualitatively detected and quantitatively analyzed ( $\mathrm{Ca}, \mathrm{Cu}, \mathrm{Fe}, \mathrm{K}, \mathrm{Mg}, \mathrm{Na}, \mathrm{P}, \mathrm{Se}, \mathrm{Zn}$ ). The measured amounts of elements were compared between 3 step and 2 step procedures which were with and without the acetone based washing step. The quantitative analysis showed that the concentrations of $\mathrm{K}, \mathrm{Na}, \mathrm{P}$, and Se were significantly decreased in hair samples with acetone-based washing $(p<0.005$ or 0.001 ) unlike those without the acetone-based washing. It implied that some minerals are lost by the acetone based washing during the sample preparation step. Therefore, the acetone based washing process is not suitable for quantifying elements in dog's hair. In addition, the results of qualitative and quantitative analysis were compared. Although there was a difference in absolute values of elemental contents in hair, the results of qualitative and quantitative analysis were significantly correlated each other. This finding suggested that the results of qualitative analysis can be used to monitor elemental contents in dog's hair.

Keywords: Canine, Elements, Hair, Inductively coupled plasma, Sample preparation

\section{INTRODUCTION}

Inductively coupled plasma (ICP) is one of a plasma source which uses an energy provided by electrical current from electromagnetic induction. ICP has been applied in an analytic technique to quantify element concentrations. Emission spectrometers using ICP is an important tool for analyzing multi-element determinants and often used to analyze trace elements in biological specimen [1-3]. Plasma is an ionized gas and a variety of samples can be introduced into plasma. For that, samples should be prepared according to the physical property [4,5]. Aqueous samples need no additional process to be introduced into a plasma and only ensured to be in solution by nitric acid $\left(\mathrm{HNO}_{3}\right)$. Solid samples are 
Kondreddy Eswar Reddy

https://orcid.org/0000-0003-2024-7724

Ki Hyun Kim

https://orcid.org/0000-0002-9834-2126

\section{Competing interests}

No potential conflict of interest relevant to this article was reported.

Funding sources

This research was supported by a grant

"Cooperative Research Program of Center for Companion Animal Research (Project No. PJ013984012019)" from the National Institute of Animal Science, Rural Development Administration, Korea.

Acknowledgements

Authors acknowledge the 2019 RDA Fellowship Program of the National Institute of Animal Science, Rural Development Administration, Korea.

Availability of data and material Upon reasonable request, the datasets of this study can be available from the corresponding author.

Authors' contributions

Conceptualization: Chun JL, Kim KH

Data curation: Bang $\mathrm{HT}$.

Formal analysis: Kim M, Lee YK.

Methodology: Jeong JY, Kim B.

Validation: Ji SY

Writing - original draft: Chun JL, Kim KH.

Writing -review \& editing: Reddy KE, Lee SD.

Ethics approval and consent to participate The animal study design was approved by IACUC review board (Approval Number: NIAS20191665). We have read and understood your journal's policies, and we believe that neither the manuscript nor the study violates any of these. This manuscript has not been published and is not under consideration by another journal. not able to be introduced into the plasma directly. Typically, acid digestion is used to dissolve solid samples. Dissolution of solid samples is usually performed by hot acid digestion. Solid biological samples like hairs need to be digested by chemicals as strong acid(s) or alkali to dissolve it [5].

Nutritional elements in vivo has been focused to investigate the relationship with the physiological functions in the body [6,7]. Nutritional elements are accumulated in blood, bones, muscles and skins and can be measured [8-10]. For example, blood and urine tests have been used to detect minerals which are considered as a parameter for nutritional status or heavy metal contamination [11-14]. However, blood can be easily affected by daily diets and it is difficult to trace the progress of a certain contamination. In addition, urine test detects only excreted minerals that it is not possible to estimate minerals in vivo. Hair can be the biological source to investigate hazardous or essential nutrient elements which are accumulated in hairs [15]. In particular, hairs are relatively stable and not easily altered. Moreover, hairs contain high concentration of elements compared to blood and urine, besides the easiness to obtain hair samples $[7,16]$.

Minerals are essential components to maintain various physiological functions in the body. Calcium, phosphorus, magnesium, sodium, chloride, potassium and sulfur are required in a large amount and ion, zinc, copper, chromium, iodine, selenium, manganeses and fluorine are needed in a small amount. It is very important to keep the balance of essential minerals. Minerals are absorbed through foods and used to body functions $[8,9,17]$. "Left-over" minerals after used are excreted by urine or accumulated in tissues like hairs and nails. Particularly, hair contains a history of minerals uptaken through foods in a long term that elements in hair have been considered as useful biological indicators of health [15].

The analysis of element compositions in hair is able to monitor an individual's nutritional status. ICP has been used to detect element compositions in hair [2]. Unlike human, the study of minerals in dogs has not been attracted. Regarding the importance of minerals dog's hair would provide various data to monitor health condition using ICP. Unfortunately, the eligibility of the hair sample preparation in ICP has not been tested. It is important to establish a proper method for the preparation of hair samples because it affects on a reliable outcome after ICP analysis. For sample introduction hair samples are required to be dissolved in liquid. Prior to the sample decomposition external contaminations are removed during washing process. In general, acetone-based washing is commonly used. Here we investigated whether the acetone based washing process during dog's hair sample preparation could affect on ICP analysis. The establishment of an effective protocol to analyze minerals in hair will facilitate the understanding the sequential health status in dogs.

\section{MATERIALS AND METHODS}

\section{Animals}

Animal experiments were approved by the Institutional Animal Care and Use Committee of the National Institute of Animal Science, South Korea (Approval number: NIAS20191665). All animals were monitored by veterinarians if needed and experiments were performed according to the approved protocols. In total twelve Beagles were enrolled in this study. Dogs were maintained in individual and separated kennels with a temperature controlled system. Dogs were fed commercial diets twice a day and water were provided ad libitum.

\section{Hair samples}

Dog's hairs were cut from 1-2 cm above the skin of back neck and collected in glass tubes. 100 $\mathrm{mg}$ of hairs were used to analyze elements for each experiment. Collected hairs from an individual dog were divided into $50 \mathrm{mg}$. Each $50 \mathrm{mg}$ of hairs were used for the control group with the ace- 
tone-based washing step and for the experimental group without the washing process.

\section{Hair washing}

$5 \mathrm{~mL}$ of acetone was added into $50 \mathrm{mg}$ of dog's hairs in a glass tube. Hairs in acetone was sonicated for $2 \mathrm{~min}$. After discarding acetone, $5 \mathrm{~mL}$ of $0.01 \%$ triton solution was added to hairs and sonicated for $2 \mathrm{~min}$. After repeating these processes twice deionized water was added prior to do another sonicate for $2 \mathrm{~min}$. At the end of the washing step hairs were dried in desiccator with silica gel.

\section{Hair digestion}

For mineralization $0.1 \mathrm{~g}$ of dried hairs were placed in a glass tube. $2.5 \mathrm{~mL}$ of nitric acid $(70 \%$ $\mathrm{HNO}_{3}$ ) were added to each sample and incubated at $80^{\circ} \mathrm{C}$ heating block for $24-48$ hours. When it became transparent deionized water were added up-to $50 \mathrm{~mL}$ in total volume. As the final process digested hairs were filtered through $0.45 \mu \mathrm{m}$ of polyvinylidene fluoride (PVDF) syringe filter (HM, Korea).

\section{ICP analysis}

The measurement of all elements was performed by ICPS-7510 (Shimadzu, Japan). The plasma gas flow was $1.0 \mathrm{~L} / \mathrm{min}$ and $\mathrm{RF}$ power was $0.8 \mathrm{~kW}$. Eighteen minerals were targeted to analyze qualitatively, i. e., arsenic $(\mathrm{As})$, boron (B), calcium $(\mathrm{Ca})$, chromium $(\mathrm{Cr})$, copper $(\mathrm{Cu})$, iron $(\mathrm{Fe})$, iodine $(\mathrm{I})$, potassium $(\mathrm{K})$, magnesium $(\mathrm{Mg})$, manganese $(\mathrm{Mn})$, molybdenum $(\mathrm{Mo})$, sodium $(\mathrm{Na})$, nickel $(\mathrm{Ni})$, phosphorus $(\mathrm{P})$, selenium $(\mathrm{Se})$, silicon $(\mathrm{Si})$, vanadium $(\mathrm{V})$, zinc $(\mathrm{Zn})$. Among them, nine elements were detected; $\mathrm{Ca}, \mathrm{Cu}, \mathrm{Fe}, \mathrm{K}, \mathrm{Mg}, \mathrm{Na}, \mathrm{P}, \mathrm{Se}, \mathrm{Zn}$. With them we performed qualitative and quantitative analysis.

\section{Statistical analysis}

Differences between the control group and the treatment group were evaluated by Student's $t$-test. Correlation coefficients between the qualitative measurements and the quantitative measurements was also analyzed by Pearson correlation analysis. Statistical significance was considered to be $p<0.05$.

\section{RESULTS AND DISCUSSION}

In dogs, minerals are involved in a variety of physiological functions. However, there is less experiment about minerals or chemicals in dog's hairs. Hair can be an effective biological sample to study elements including minerals because it is easy to obtain without any pain or surgical process [15,17]. Moreover, hair grows that it is possible to obtain accumulated information of elements. ICP system has been used to analyze elements in various biological samples including hairs [10]. To collect reliable results, it is required to process a proper pre-treatment step which prevents from any exogenous contamination $[5,18]$. On the other hand, it is important to keep endogenous elements without losing that allows to measure the actual amount of elements accumulated in samples.

Here, we tested whether the pre-treatment process affect on the measurement of elements in dog's hair samples. To measure minerals there were 3 steps: washing, sample digestion and ICP analysis. Dog's hair samples were processed through the acetone-based washing step which has been used as a common method in ICP analysis. There were three steps as a usual method for the control group and two steps as the test for the treatment group without washing. We targeted eighteen elements and $\mathrm{Ca}, \mathrm{Cu}, \mathrm{Fe}, \mathrm{K}, \mathrm{Mg}, \mathrm{Na}, \mathrm{P}, \mathrm{Se}$, and $\mathrm{Zn}$ were detected after standardized in the qualitative analysis (Table 1). $\mathrm{Ca}, \mathrm{K}, \mathrm{Mg}, \mathrm{Na}$, and $\mathrm{P}$ are classified in macro elements which are usually expressed in terms of milligrams per 1,000 kcal. $\mathrm{Ca}$ and $\mathrm{P}$ are essential for internal skeleton. $\mathrm{Ca}$, 
Table 1. The effect of washing step on the qualitative analysis of elements in dog's hairs

\begin{tabular}{lccccccccc}
\hline & $\mathbf{C a}$ & $\mathbf{C u}$ & $\mathbf{F e}$ & $\mathbf{K}$ & $\mathbf{M g}$ & $\mathbf{N a}$ & $\mathbf{P}$ & $\mathbf{S e}$ & $\mathbf{Z n}$ \\
\hline 2 step $(\mu \mathrm{g} / \mathrm{g})$ & $1,382,142.5$ & 351.2 & 310.4 & 1,146 & 540.8 & $2,478.6$ & 866.6 & 56.3 & $1,715.2$ \\
3 step $(\mu \mathrm{g} / \mathrm{g})$ & $1,311,745.1$ & 373.9 & 254.9 & 436.9 & 543.3 & 917.3 & 673.6 & 56.8 & $1,894.1$ \\
Difference $(\%)$ & -5.1 & 6.4 & -17.9 & -61.9 & 5 & -63 & -22.3 & 9 & 10.4 \\
Correlation & 0.9 & 0.9 & 0.6 & 0.4 & 0.9 & 0.4 & 0.7 & 0.9 & 0.6 \\
$t$-test & 0.745 & 0.158 & 0.242 & 0.012 & 0.98 & 0.002 & 0.096 & 0.952 & 0.026 \\
\hline
\end{tabular}

Values are mean.

Table 2. The effect of washing step on the quantitative analysis of elements in dog's hairs

\begin{tabular}{|c|c|c|c|c|c|c|c|c|c|}
\hline & $\mathrm{Ca}$ & $\mathrm{Cu}$ & $\mathrm{Fe}$ & $\mathbf{K}$ & Mg & $\mathrm{Na}$ & $\mathbf{P}$ & Se & $\mathrm{Zn}$ \\
\hline 2 steps $(\mu \mathrm{g} / \mathrm{g})$ & 712.1 & 0 & 0 & $1,326.5$ & 63.7 & 2,968 & 428.7 & 4.1 & 46.8 \\
\hline 3 steps $(\mu \mathrm{g} / \mathrm{g})$ & 627.7 & 0 & 0 & 122.6 & 62.1 & 369.1 & 249.5 & 2.3 & 59.3 \\
\hline Correlation & 0.7 & 0 & 0 & 0 & 0.9 & 0.1 & 0.7 & 0.9 & 0.1 \\
\hline$t$-test & 0.602 & 0 & 0 & $<.000$ & 0.948 & $<.000$ & 0.004 & $<.000$ & $<.000$ \\
\hline
\end{tabular}

Values are mean.

$\mathrm{Mg}, \mathrm{K}$, and $\mathrm{Na}$ have important roles in nervous impulse, muscle contraction and cell signaling. Fe, $\mathrm{Zn}, \mathrm{Cu}, \mathrm{Mn}, \mathrm{I}$, and Se are considered to be trace elements which are needed in a smaller amount in pet foods. Usually, trace elements are involved in enzymatic reactions. Fe, Zn, and I are important in protein and hormone structures.

In qualitative analysis, $\mathrm{Ca}, \mathrm{Fe}, \mathrm{K}, \mathrm{Na}$, and $\mathrm{P}$ are detected 5.1, 17.9, 61.9, 63, and 22.3 less after 3 step process than those after 2 step process (Table 1). The amount of $\mathrm{Zn}$ is detected $10.4 \%$ more in 3 step process than those in 2 step process (Table 1). Especially, $\mathrm{K}$ and $\mathrm{Na}$ were significantly decreased. In quantitative analysis, $\mathrm{Cu}$ and $\mathrm{Fe}$ were not detected (Table 2). $\mathrm{Ca}, \mathrm{K}, \mathrm{Mg}, \mathrm{Na}, \mathrm{P}$, and $\mathrm{Se}$ were decreased $11.8 \%, 90.8 \%, 2.5 \%, 87.6 \%, 41.8 \%$, and $43.7 \%$ in 3 step process compared to those in 2 step process (Table 2). Moreover, $\mathrm{K}, \mathrm{Na}, \mathrm{P}$, and Se were significantly decreased. It implied that the acetone based washing process which has been considered to be a standard method would result in losing some endogenous minerals during pre-treatment process. In addition, we compared the results from qualitative and quantitative analysis (Fig. 1). The values of qualitative analysis had linearized functional relationship with those of quantitative analysis. It supported that the qualitative analysis would be used to quantify elements in hairs as the semi-quantitative analysis.

Hair contains a sequential and various information including nutritional and toxic elements [7]. The content of elements in hair has been used as a marker of nutritional and physiological status of animals. However, in dogs, hair has not been used as much as its value as a biological parameter. In addition, the comprehensive analysis of untargeted elements has been developed and applied using metallomic analysis [19]. At the same time, it is important to establish the analytical condition of minerals because the comprehensive analysis is affected by the sample preparation process [18,20,21]. This study emphasized the need for the establishment of the hair sample preparation for ICP analysis. Meanwhile we also showed that the qualitative analysis would be another method to quantify minerals in hair by using ICP. The results would contribute to develop an effective method to analyze minerals in dog's hair.

\section{REFERENCES}

1. Schierle C, Otto M. Qualitative and semi-quantitative analysis in ICP-AES using multivariate 
$\mathrm{Ca}$
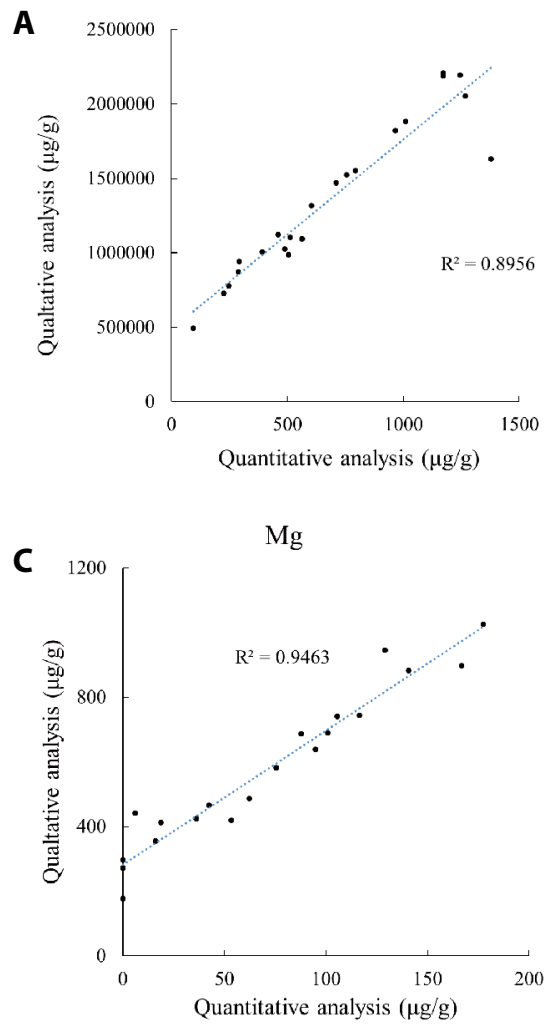

$\mathrm{P}$

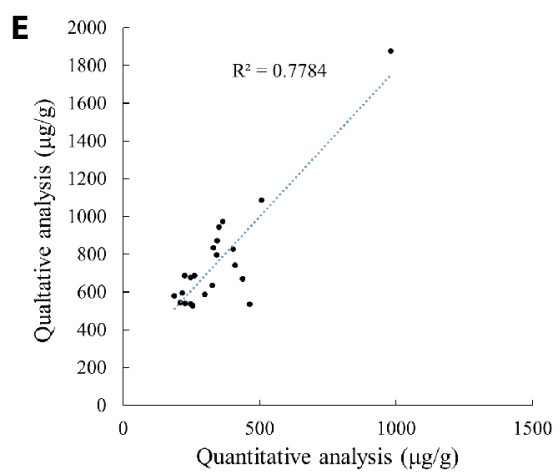

$\mathrm{Zn}$

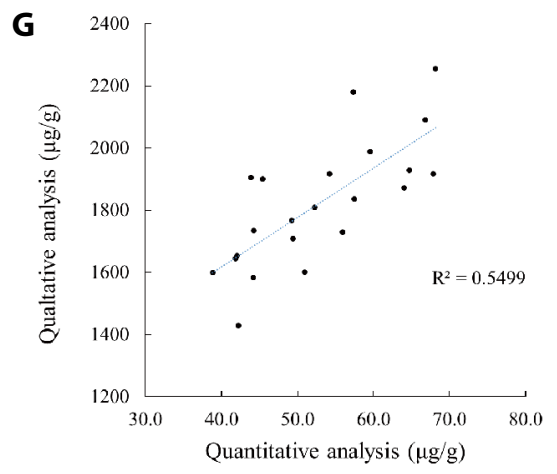

$\mathrm{K}$
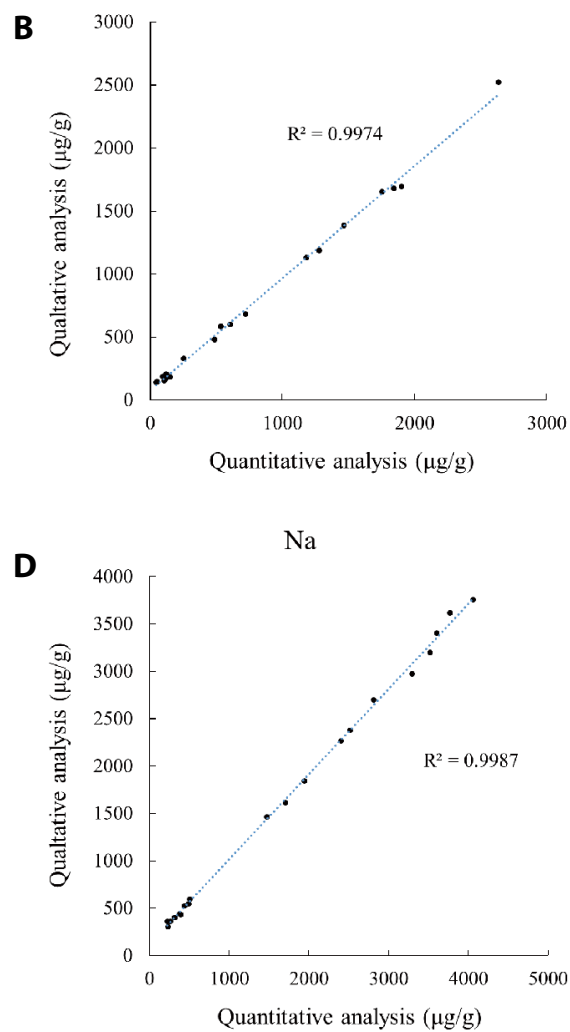

$\mathrm{Se}$

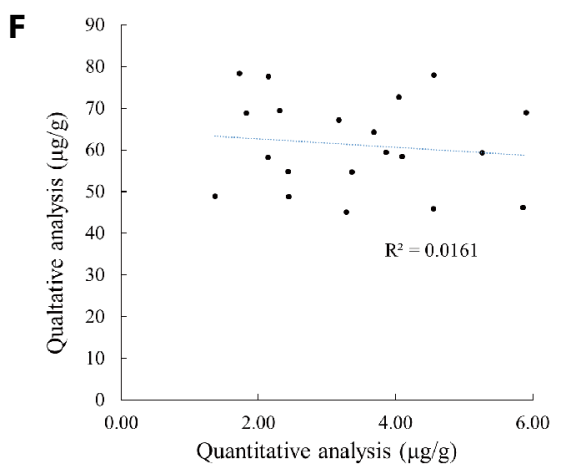

Fig. 1. Correlation of quantitative and qualitative analysis in ICP. The correlation between quantitative and qualitative data of (A) calcium, (B) potassium, (C) magnesium, (D) sodium, (E) phosphorus, (F) selenium, (G) zinc. ICP, inductively coupled plasma. 
calibration. Microchim Acta. 1994;113:357-72.

2. Puchyr RF, Bass DA, Gajewski R, Calvin M, Marquardt W, Urek K, et al. Preparation of hair for measurement of elements by inductively coupled plasma-mass spectrometry (ICP-MS). Biol Trace Elem Res. 1998;62:167-82.

3. Kim KH, Ishizaki N, Iguchi E, Funaba M, Matsui T. Effect of magnesium deficiency on various mineral concentrations in rat liver. Biol Trace Elem Res. 2011;144:865-71.

4. Amaral CDB, Nobrega JA, Nogueira ARA. Sample preparation for arsenic speciation in terrestrial plants: a review. Talanta. 2013;115:291-9.

5. Pappas RS. Sample preparation problem solving for inductively coupled plasma-mass spectrometry with liquid introduction systems I. Solubility, Chelation, and memory effects. Spectroscopy. 2012;27:20-31.

6. Aguilera-Tejero E, Lopez I, Estepa JC, Mayer-Valor R, Almaden Y, Concepcion MT, et al. Mineral metabolism in healthy geriatric dogs. Res Vet Sci. 1998;64:191-4.

7. Wolowiec P, Michalak I, Chojnacka K, Mikulewicz M. Hair analysis in health assessment. Clin Chim Acta. 2013;419:139-71.

8. Kastenmayer P, Czarnecki-Maulden GL, King W. Mineral and trace element absorption from dry dog food by dogs, determined using stable isotopes.J Nutr. 2002;132:1670-2.

9. Dillitzer N, Becker N, Kienzle E. Intake of minerals, trace elements and vitamins in bone and raw food rations in adult dogs. Br J Nutr. 2011;106:S53-6.

10. Baltussen E, Schoutsen D, Noij T, Kim YH, Kim HK, Suh KH. ICP-MS in drug development: high-throughput analysis of strontium and calcium in bone, tissue and plasma. Bioanalysis. 2013;5:2875-87.

11. Pereira R, Ribeiro R, Goncalves F. Scalp hair analysis as a tool in assessing human exposure to heavy metals (S. Domingos mine, Portugal). Sci Total Environ. 2004;327:81-92.

12. De Azevedo SV, Moreira FR, Campos RC. Direct determination of tin in whole blood and urine by GF AAS. Clin Biochem. 2013;46:123-7.

13. Lee JY, Kim JH, Choi DW, Lee DW, Park JH, Yoon HJ, et al. The association of heavy metal of blood and serum in the Alzheimer's diseases. Toxicol Res. 2012;28:93-8.

14. Popot MA, Ho ENM, Stojiljkovic N, Bagilet F, Remy P, Maciejewski P, et al. Interlaboratory trial for the measurement of total cobalt in equine urine and plasma by ICP-MS. Drug Test Anal. 2017;9:1400-6.

15. Pozebon D, Scheffler GL, Dressler VL. Elemental hair analysis: a review of procedures and applications. Anal Chim Acta. 2017;992:1-23.

16. Sitrin MD. Absorption of water-soluble vitamins and minerals. In: Leung PS, editor. The gastrointestinal system: gastrointestinal, nutritional and hepatobiliary physiology. New York, NY: Springer; 2014. p. 211-36.

17. Esteban $\mathrm{M}$, Castano A. Non-invasive matrices in human biomonitoring: a review. Environ Int. 2009;35:438-49.

18. Verrey D, Durand S, Thomas O, Lelevrier V, Quenel P, Le Bot B. A new washing procedure for inorganic element analysis of hair.J Expo Sci Environ Epidemiol. 2019;29:706-17.

19. Timerbaev A, Sturup S. Analytical approaches for assaying metallodrugs in biological samples: recent methodological developments and future trends. Curr Drug Metab. 2012;13:272-83.

20. Seidel S, Kreutzer R, Smith D, McNeel S, Gilliss D. Assessment of commercial laboratories performing hair mineral analysis. JAMA. 2001;285:67-72.

21. Mikulewicz M, Chojnacka K, Gedrange T, Gorecki H. Reference values of elements in human hair: a systematic review. Environ Toxicol Pharmacol. 2013;36:1077-86. 